\title{
Application of Concrete Segment Panels for Reduction of Torsional Vibration Responses of Girder Bridges
}

\author{
Jong-Won Kwark ${ }^{1, a}$, Jae-Yoon Kang ${ }^{1}$, Sung-Yong Park ${ }^{1}$ and Keun-Taek Kim² \\ ${ }^{1}$ Korea Institute of Civil Engineering and Building Technology, Structural Engineering Research Institute, Goyang, 411-712 Korea \\ ${ }^{2} B N G$ Consultants, Sungnam, 463-825 Korea
}

\begin{abstract}
The dynamic flexural behaviour of railway bridges is influenced by the torsional behaviour, and the flexural response tends to be amplified as the flexural natural frequency (the 1st vibrational mode) and torsional frequency (the 2 nd vibrational mode) are adjoining. To avoid this phenomenon, the installation of concrete segment panels was considered for the reinforcement of torsional stiffness by connecting bottom flanges between girders. This alternative can increase the torsional stiffness by providing the restraint in torsional vibration and reduce the influence of torsional behaviour on the amplification of flexural responses. This study investigates the effect of the concrete segment panels on the control of torsional dynamic responses and on the increment of torsional frequency. The excitation tests on a full-size bridge specimen with $30 \mathrm{~m}$ span length were conducted with respect to the installation length of concrete panels up to $7 \mathrm{~m}$ from each ends. The results show that the installation of concrete segment panel augments the torsional frequency up to $22 \%$ while the flexural frequency keeps its original value. It is concluded that the dynamic behaviour of girder bridges can be controlled by the adjustment of installation length of concrete panels, thereby reducing the torsional responses.
\end{abstract}

\section{Backgrounds}

The dynamic response of a railway bridge occurs through the difference in the periods of its flexural and torsional behaviours. The overall dynamic response of the structural system increases under the passage of vehicles due to the superposition of the dynamic responses as much as the natural frequencies of the flexural $\left(1^{\text {st }}\right.$ vibrational mode) and torsional ( $2^{\text {nd }}$ vibrational mode) modes become closer to each other. In order to minimize the influence resulting from the superposition of these vibrational modes, a difference of at least $20 \%$ is recommended between the natural frequencies of the $1^{\text {st }}$ and $2^{\text {nd }}$ vibrational modes. However, this difference is generally smaller than $20 \%$ in the case of the girder-type railway bridge with concrete track and makes it very prone to see its dynamic response amplified due to the mode superposition.

Accordingly, this study proposes to modify the structural system in a way enabling it to control its torsional behaviour without affecting its flexural behaviour through the installation of articulated reinforcement panels linking the bottom flanges of the girders as shown in Figure 1 so as to improve the dynamic behaviour and restrain the torsional behaviour known to be the weakness of the railway girder bridge. A full-scale prototype was fabricated and subjected to forced vibration test using a vibrator to verify the efficiency of the proposed solution through the comparative analysis of the change in the natural frequencies of the flexural and torsional modes and characteristic values like the damping ratio.



Figure 1. Torsional reinforcement of girder bridge.

\section{Summary of Forced Vibration Test}

\subsection{Prototype}

The full-scale prototype adopted for the forced vibration test is a single span, double girder bridge with a span length of $30.0 \mathrm{~m}$, a distance of $29.1 \mathrm{~m}$ between supports, and girder depth of $2.0 \mathrm{~m}$. The girders are distant by 2.0 $\mathrm{m}$ and support a deck with width of $4.0 \mathrm{~m}$ and thickness of $29.5 \mathrm{~cm}$. Figure 2 illustrates the cross-section of the prototype and shows a view of the installed reinforcing panels.

\footnotetext{
${ }^{\text {a }}$ Corresponding author: origilon@kict.re.kr
} 


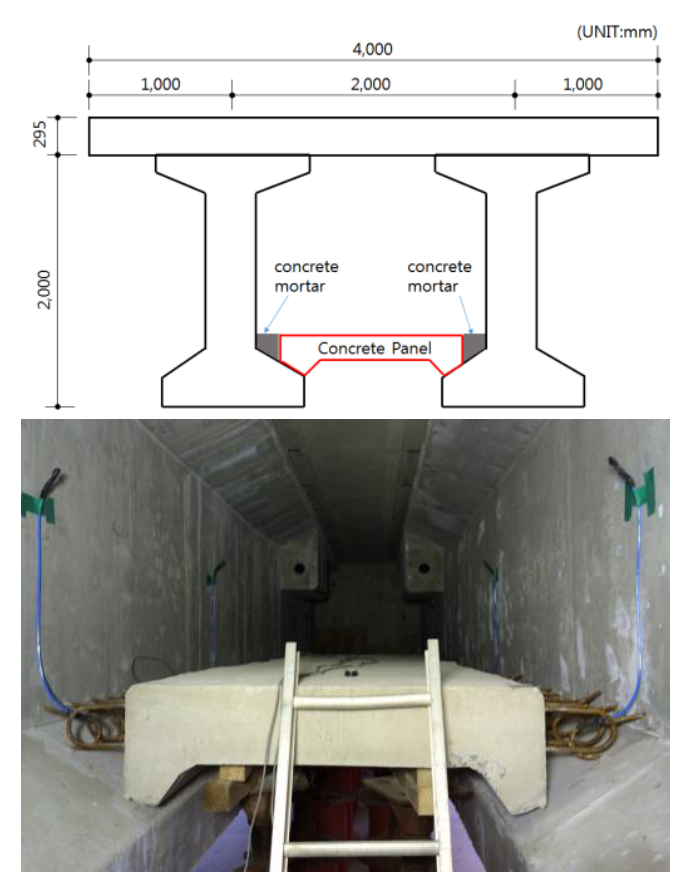

Figure 2. Cross-section of girder bridge prototype and view of installed reinforcement panels.

The torsional reinforcement panels are made of concrete with length of $1,160 \mathrm{~mm}$, width of $500 \mathrm{~mm}$ and thickness of $200 \mathrm{~mm}$. The installation proceeds by first disposing the panels on the flanges inside the girder, connecting the girders' webs and panels by hoop reinforcement and, finally by completing the connection by cast-in-place non-shrinkage mortar.

\subsection{Formatting the text}

The test variable is the installed length of the torsional reinforcement panels resulting in a total of 4 cases: nonreinforced case (RP-0), and cases with installed length of 2 $\mathrm{m}$ (RP-2), $4 \mathrm{~m}$ (RP-4), and $7 \mathrm{~m}$ (RP-7). For each of these 4 cases, forced vibration test is conducted 3 times under the following conditions. A rotary-type inertial vibrator is used so as to generate artificial vibration up to a frequency of 10 Hz. In Figure 3, LC-1 indicates the vibration condition inducing pure bending mode of the prototype, and LC-2 and LC-3 stand for the vibration condition inducing vibrational mode in torsion. Specifically, case LC-1 is the centered forced vibration at mid-span, case LC-2 is the eccentric forced vibration at mid-span, and case LC-3 is the eccentric forced vibration at 5/12 spot.

Forced vibration operates as follows: the natural frequency of the structural system is obtained by forced vibration up to $10 \mathrm{~Hz}$; the natural frequencies of the flexural and torsional modes are separated and obtained through the analysis of the acceleration response, and resonance is provoked in each vibrational mode at the concerned frequencies.

For the sensors, accelerometers are used to analyse the vibrational modes of the deck and girders, displacement sensors are adopted to analyse the displacement of the girders, and strain gages are installed to analyse the stress in the reinforcement connecting the reinforcement panels and the girders. As shown in Figure 3 , the accelerometers are installed at spacing of $5 \mathrm{~m}$ at the end of the cantilevered arms of the deck to provide measurement of the acceleration in the vertical direction at 10 spots. The vertical displacement is measured at the centre of the span using a displacement sensor.

\section{Results of Forced Vibration Test}

\subsection{Change of natural frequencies}

Table 1 and Figure 4 present the measured natural frequencies with respect to the modification of the structural system by the installation of the torsional reinforcement panels.

Table 1. Change of natural frequencies.

\begin{tabular}{|c|c|c|}
\hline $\begin{array}{c}\text { Reinforcement } \\
\text { case }\end{array}$ & $\begin{array}{c}\mathbf{1}^{\text {st }} \text { mode (bending) } \\
(\mathbf{H z})\end{array}$ & $\begin{array}{c}\mathbf{2}^{\text {nd }} \text { mode (torsion) } \\
(\mathbf{H z})\end{array}$ \\
\hline RP-0 & 4.402 & 6.862 \\
\hline RP-2 & 4.456 & 7.308 \\
\hline RP-4 & 4.434 & 7.672 \\
\hline RP-7 & 4.412 & 8.421 \\
\hline
\end{tabular}

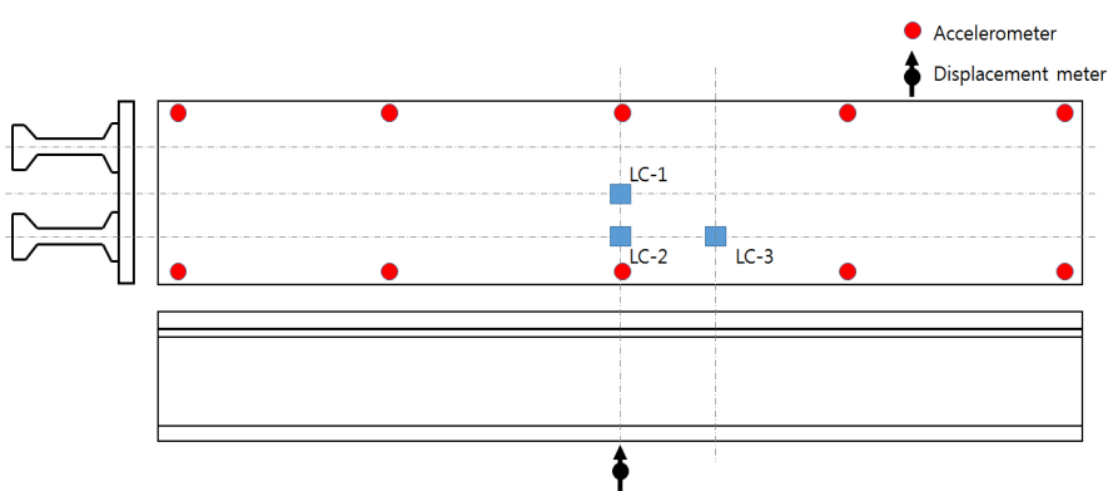

Figure 3. Layout of sensors and position of vibrator for forced vibration test. 


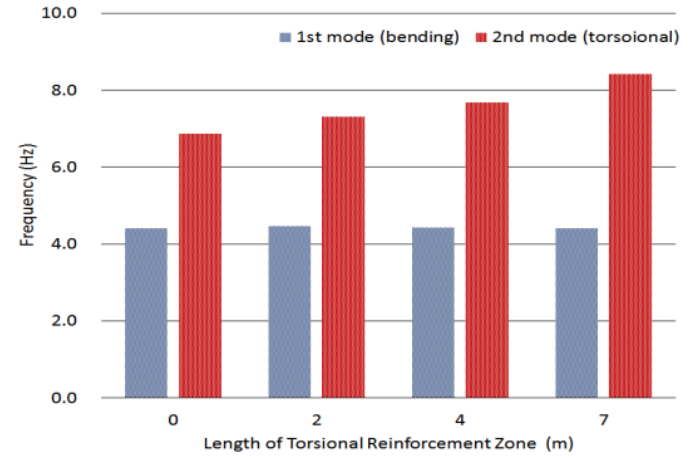

Figure 4. Comparison of change of natural frequencies.

The bending mode frequency shows practically no change according to the installation of the panels and remains bounded between 4.402 and $4.456 \mathrm{~Hz}$. This is due to the absence of contribution of the panels in the increase of the flexural rigidity of the whole bridge since the panels are not continuous but are partitioned. The torsional mode frequency increases linearly with the enlargement of the installed length of the panels. The separation of the natural frequencies of the $1^{\text {st }}$ and $2^{\text {nd }}$ modes by the installation of the torsional reinforcement panels can also be verified.

Figure 5 plots the change in the ratio of the natural frequency of the $2^{\text {nd }}$ mode to that of the $1^{\text {st }}$ mode $\left(f_{2} / f_{1}\right)$ according to the installed length of the panels. The natural frequency ratio is seen to increase linearly in proportion to the installed length of the panels.

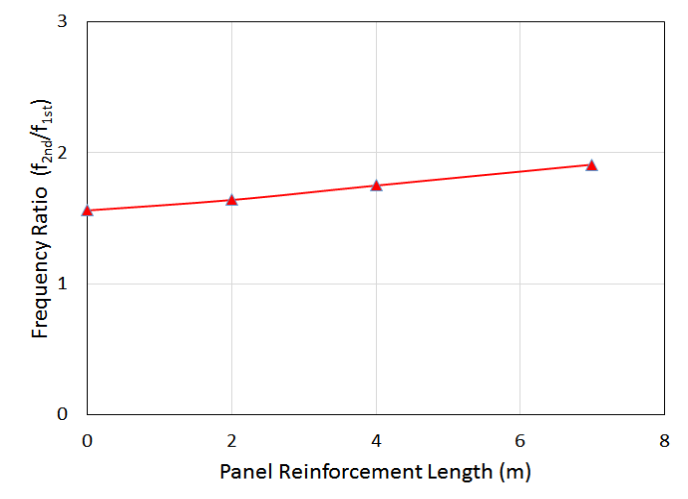

Figure 5. Change of natural frequency ratio.

\subsection{Change of damping ratio}

Table 2 arranges the damping ratio according to the change in the installed length of the torsional reinforcement panels. It can be seen that there is no clear proportionality in the increase of the damping ratio with respect to the enlargement of the installed length. The damping ratio relative to the bending mode remains in a definite range around $1.24 \pm 0.25 \%$. Besides, the damping ratio relative to the torsional mode tends to reduce slightly with the enlargement of the installed length of the panels within the range of $1.53 \pm 0.09 \%$.

Figure 6 compares the change of the damping ratio in the bending mode and torsional mode.
Table 2. Change of damping ratio.

\begin{tabular}{|c|c|c|}
\hline $\begin{array}{c}\text { Reinforcement } \\
\text { case }\end{array}$ & $\begin{array}{c}\mathbf{1}^{\text {st }} \text { mode (bending) } \\
\mathbf{( \% )}\end{array}$ & $\begin{array}{c}\mathbf{2}^{\text {nd }} \text { mode (torsion) } \\
(\mathbf{\%})\end{array}$ \\
\hline RP-0 & 1.18 & 1.63 \\
\hline RP-2 & 1.49 & 1.59 \\
\hline RP-4 & 1.10 & 1.41 \\
\hline RP-7 & 1.18 & 1.50 \\
\hline
\end{tabular}

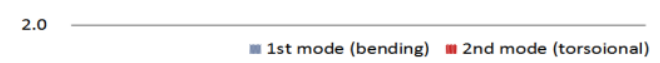

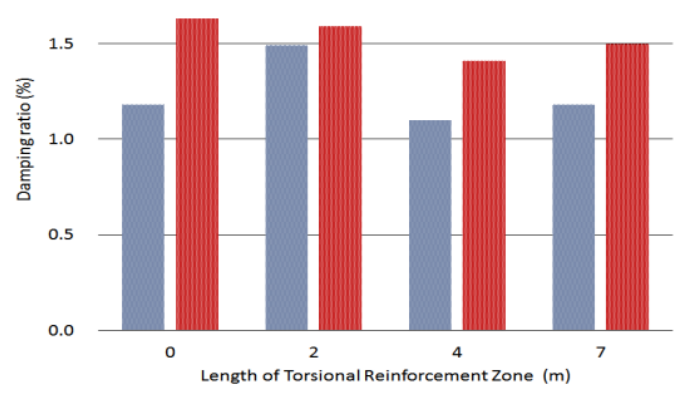

Figure 6. Comparison of change of damping ratio.

\subsection{Analysis of stress in the connection of the panels}

The change in the stress was measured during the dynamic test by means of strain gages attached to the connecting reinforcement between the girders and torsional reinforcement panels. Table 3 arranges the maximum stress developed in the connecting reinforcement at bending and torsional resonance with respect to the change in the installed length of the panels. The results show that the maximum stress developed in the panel connecting reinforcement in all the considered lengths remained below $2 \%$ of the yield strength of the reinforcement during resonance.

Table 3. Maximum stress in panel connection.

\begin{tabular}{|c|c|c|c|}
\hline \multicolumn{2}{|c|}{ Reinforcement case } & $\begin{array}{c}\text { Max. stress at } \\
\text { flexural } \\
\text { resonance } \\
\text { (MPa) }\end{array}$ & $\begin{array}{c}\text { Max. stress at } \\
\text { torsional } \\
\text { resonance } \\
\text { (MPa) }\end{array}$ \\
\hline \multirow{2}{*}{ RP-2 } & Tension & +0.2 & +2.6 \\
\cline { 2 - 3 } & Compression & -0.2 & -4.6 \\
\hline \multirow{2}{*}{ RP-4 } & Tension & +0.8 & +2.8 \\
\cline { 2 - 2 } & Compression & -0.8 & -4.0 \\
\hline \multirow{2}{*}{ RP-7 } & Tension & +0.2 & +2.8 \\
\cline { 2 - 2 } & Compression & -0.6 & -3.0 \\
\hline
\end{tabular}

\section{Conclusions}

This study proposed a method installing torsional reinforcement panels made of concrete to strengthen the torsional rigidity of the girder railway bridge known to be prone to torsional behaviour. Forced vibration test was performed on a full-scale girder bridge prototype with span length of $30 \mathrm{~m}$ and equipped with the proposed 
torsional reinforcement panels to examine their effect on the improvement of the dynamic behaviour. The following conclusions can be drawn.

The installation of the torsional reinforcement panels enabled to improve the torsional rigidity of the girdertype railway bridge and was verified to increase the natural frequency in the torsional mode. The use of articulated panels was seen to have no contribution to the increase of the flexural rigidity and practically no change in the flexural natural frequency was observed.

The installation of the torsional reinforcement panels provoked clear separation between the flexural and torsional mode natural frequencies. It was also verified that the natural frequency ratio of the $2^{\text {nd }}$ mode to the $1^{\text {st }}$ mode increased proportionally to the installed length of the reinforcing panels. When undesirable dynamic behaviour occurs following the superposition of response under dynamic loading due to the closeness of the natural frequencies of the bending and torsional modes, the proposed torsional reinforcement panels appeared to be effective for the improvement of the dynamic behaviour by separating the flexural behaviour and torsional behaviour through the modification of the structural system.

The damping ratio seemed to be practically not influenced by the installation of the reinforcement panels and remained similar to that of the case without reinforcement.

When the girder webs and reinforcement panels are connected by means of rebar, the stress developed in the rebar remained minimal with values below $5 \mathrm{MPa}$. This indicated that the stress added in the girder by the interaction of the panels and girder connection during the installation of the panels can be neglected.

These conclusions reveal that the installation of the proposed torsional reinforcement panels in the girdertype railway bridge can prevent the superposition of the flexural and torsional modes and reduce the dynamic response by means of the strengthening of the torsional rigidity. The proposed torsional reinforcement panels offer thus an effective alternative for the improvement of the dynamic characteristics in girder railway bridges currently in service experiencing large dynamic response or presenting risk of resonance during the passage of convoys. 